Portland State University

PDXScholar

3-1-2018

\title{
Babel from Scratch: Examining the Impact and Usage of Constructed Languages in Literature
}

\author{
Estephan G. Campisi \\ Portland State University
}

Follow this and additional works at: https://pdxscholar.library.pdx.edu/honorstheses

\section{Let us know how access to this document benefits you.}

\section{Recommended Citation}

Campisi, Estephan G., "Babel from Scratch: Examining the Impact and Usage of Constructed Languages in Literature" (2018). University Honors Theses. Paper 522.

https://doi.org/10.15760/honors.527

This Thesis is brought to you for free and open access. It has been accepted for inclusion in University Honors Theses by an authorized administrator of PDXScholar. Please contact us if we can make this document more accessible: pdxscholar@pdx.edu. 


\title{
PORTLAND STATE UNIVERSITY
}

An Undergraduate Honors Thesis Submitted to the

University Honors College

$\&$

Department of English

In partial fulfillment of the requirements for the degree of Bachelor of Arts

Babel From Scratch: Examining The Impact and Usage Of

Constructed Languages in Literature

Written By: Estephan Campisi

Thesis Advisor: Dr. Kimberley Brown

Submitted On: 3/23/18

\begin{abstract}
:
Constructed languages are becoming more ubiquitous in literature and popular fiction. Ever since J.R.R. Tolkien's The Lord of the Rings, authors in speculative fiction have developed their own created languages for the purposes of illustrating fictional cultures. This paper examined conlangs from an artistic and literary perspective by asking two questions: first, how do conlangs operate in a literary text and enhance a reading of that text through its inclusion, and second, how are conlangs valid as their own art projects? This first involved a historical and literary lens on the background of constructing languages by reviewing the literature on conlangs up to now, and then using independent research to come to new conclusions about the subject. This included an interview with a noteworthy language creator for several popular fiction franchises. In addition, this paper also included a brief phonological analysis of two different languages from two notable speculative fiction authors in the context of the work that they inhabit, by summarizing their phonetic inventories and phonotactics. The analysis concluded that the phonology of the work communicates some level of cultural knowledge to the reader, while also helping place the texts within the larger realm of certain literary movements, such as modernism and postmodernism, while also speculating on the validity of created languages themselves as art forms with their own unique history and potential for impact on the cultural landscape.
\end{abstract}




\section{Introduction}

Language is a mysterious device. It is inherent to our human existence, critical to our success and hopeful continuation as a species, and its origins are cloaked in uncertainty. Language has been mythologically understood as an aspect of humanity that is outside of our own control, and one of the most well known of these myths is the biblical story of the Tower of Babel. This is a melancholic tale of mankind's hubris, in which united peoples across the land constructed a heavens-reaching structure, only to be afflicted with the curse of not being able to understand one another. This caused the construction to halt and the tower to wither away and fall as the once-singular humanity fell into ethnic factions. A parable with a shaky lesson-one is not sure whether it preaches the importance of communication or against multicultural dialogue - the theoretical implications are explicit: language is beyond human control. We are given our languages, and from there on we adopt ourselves into them. But that is not really true. We understand language now more than ever, and we will continue to expand this understanding into the future. To understand is to master, with some people taking that divine gift into their own hands, constructing languages themselves.

This thesis analyzes that phenomenon from the perspective of how these constructed languages function as art. Constructed languages, or conlangs, have become somewhat ubiquitous in popular entertainment as of late, seen in speculative fiction film and TV productions, such as Star Trek, Game of Thrones or Lord of the Rings. Watch an episode of Star Trek and you will likely come into contact with the language of Klingon. Game of Thrones has several languages that are spoken in the world of Westeros but have no natural roots in the real world. But conlangs have existed before the current cultural zeitgeist, and they will exist long 
after. They have their handprint in literature, most particularly speculative fiction, and as that genre has become more popular, so have conlangs. Because of this, it is important to examine what exactly they are and why they are important to the literature we hold close.

This project will examine conlangs from an artistic and literary perspective by asking two questions: first, how do conlangs operate in a literary text and enhance a reading of that text through its inclusion, and second, how are conlangs valid as their own art projects?

\section{Literature Review}

In this literature review, I will examine what has already been written on the phenomenon of conlangs, the significance of this work, and what crucial areas on conlangs in art have been overlooked. Conlangs are a lesser-known subject and have very few scholars working on their study and history, but there are some authors who have done extensive work on their historicization and implications for the larger world. It is important to address this because conlangs nay be a niche study academically, but their proliferation in popular entertainment is undeniable.

Arika Okrent's In the Land of Invented Languages (2009), is perhaps the most comprehensive catalogue of various important conlangs throughout history, including Esperanto, Loglan, and Klingon. A key element of this text is the way Okrent connects conlangs to a larger historical and scholarly framework. This is to show how conlangs do not operate in a historical vacuum, but are rather themselves both product and effect on the past, which raises implications for their effect on the future. For instance, in her section on Esperanto, she writes about its creator, Ludwik Zamenhof, and the historical forces which propelled him to create this language 
of peaceful universality. This also chronicled how the rise and resistance to nationalism allowed this language to gain popularity despite its humble beginnings, and its implications for not just the future of conlanging, but also global politics as a whole. Her section on Loglan and its inventor, James Cooke Brown, examines its relationship to the scholarly community of linguists and its dialogue with the Whorfian hypothesis, a proposal that the language one speaks affects the way one thinks. Though there is some evidence to support linguistic relativity (Boroditsky, 2011), proving the hypothesis is exceptionally difficult without some form of control or quantifiable evidence, which is what Loglan sought to provide by acting as a purely logical language. This is another way in which Okrent's work is significant to the study of conlangs as well, as it examines the motive for the creation of many of these languages, which can range from the pursuit of world peace, as with Zamenhof, or a secretive hobby, as with Tolkien. This creates a distinction between why the languages are created and how they are used, dividing them between languages for auxiliary communication like Esperanto or languages for the inclusion in works of art. Some scholars have done work in understanding how these languages can be used for more material purposes, such as examining how conlangs can be used in the classroom to explain linguistic features without having to grapple with the irrational inconsistencies of a natural language (Sanders, 2016).

The languages that are created for the specific purposes of art, or artlangs, as David J. Peterson and the larger conlanging community refers to them (2015), have also been especially examined by other authors, such as Adams (2011) and Cheyne (2008). The way these two authors differentiate their work is the focus on linguistic aspects as opposed to literary aspects. In Adams' From Elvish to Klingon: Exploring Invented Languages (2011), he, along with other authors who specialize in particular conlangs, catalogues various invented languages as they 
appear in fiction by their linguistic features. For instance, Klingon has a section on its phonological and syntactical features, as well as some background as to the fictive culture and history that the language inhabits. This is significant as it lends credence to the fact that these languages are not just false images of true tongues, but rather fully fleshed out languages that can be learned and spoken in real life. Linguistically breaking down and deconstructing the languages not only give them a sense of validity on a larger scale, but they also offer clues as to what the process of creating these languages was like, how much in depth the work was, and what parts were consciously chosen as opposed to unconsciously. In contrast, Cheyne's work "Created Languages in Science Fiction" (2008) forgoes the examination of the linguistic features of these languages and instead indexes the literary purpose these languages fulfill in the texts in which they appear. For instance, she classifies various languages by whether they are used to test the Whorfian hypothesis, are used to characterize a particular culture, or to emblematize the alien, among others. This is important for work in studying conlangs as it shows the significance of how these conlangs affect readings of the work; they are not simply background material, or window dressing, but actual elements of the work that should be carefully considered when thinking about how the work is explicated and meaning is produced.

This appears to be an expansion of the work Bianco produces in his article "Invented languages and new worlds" (2004) which examines conlangs in fiction, specifically on whether they are produced a priori (completely original) or a posteriori (based off of an existing language) and the implications that has for the languages in their construction, linguistic features, and their readings. Bianco writes case examinations of several conlangs, including the various languages of Middle Earth, and uses some of their linguistic features to apply to their readings, which is similar to what I also planned on accomplishing and used it partially as inspiration for 
my own work.

The most critical text for this work, however, would be David J. Peterson's The Art of Language Invention (2015). Peterson is a linguist and avid conlanger who has worked on several conlangs for fictional properties such as the Marvel Cinematic Universe and the TV show Defiance, but his most notable work would be the languages of Dothraki and Valyrian for the HBO show Game of Thrones, based off of the George R.R. Martin book series A Song of Ice and Fire. In The Art of Language Invention, Peterson takes his own languages which he has developed and uses them as case studies to show how certain aspects of a conlang are developed, the particular challenges of constructing a language, and what parts of a language one needs to take into account when one wishes to construct their own. In all, this work acts mostly as a guide for aspiring conlangers, offering resources and the required vocabulary, or as a peek into the creative process that some may be interested in. This is significant to conlang literature because not only does it have a wealth of knowledge in terms of the current working lexicon for conlangs, a in depth look into the creative process of conlanging, and the required elements for a flourishing conlang, but it also has a personal history with how conlanging as a subculture has risen since the advent of the internet and listservs. This is important to understanding conlanging not just as historicized phenomena, but a current active subculture and art form.

What we have in the literature then, are three main themes: conlangs as historical linguistic phenomena, conlangs as literary devices, and conlangs as art projects. With the exception of Bianco, these themes in the literature rarely intersect. What is left to be explicated is that intersection. I then worked off of three lesser-examined areas of conlangs in the literature: one, the intersection between artistic readings and the linguistic features; two, the presence of conlangs as art projects and their literary worth;and three, the intersection between history and 
conlangs as art. In Bianco (2004) we see that languages can be informed by the literary context, but what if one were to look the other way, turn the screw, and see that the literary context can be informed by the language? By isolating a single linguistic feature, whether it be the syntax, morphology, or phonology, one wonders what that feature can say about the work that would not necessarily be communicated by other aspects of the work already. As these languages are massive efforts, one imagines that they are not made to be included in the work for lack of purpose; one has to assume that the language is crucial to the work, and because it is crucial, there is some semblance of meaningful dimension to the language that the rest of the work does not necessarily communicate. Since they are languages first and foremost, that meaning must inhabit the linguistic features of the language. One can think of the linguistic features as the text; just as one reads the text to discern meaning from a work, one must read the language's features to discern meaning from the language. In addition, the intersection of conlangs as art and as literary devices is important because one can use the meaning of their role as literary devices to support the concept that conlangs themselves carry artistic meaning. It is easy to say that conlangs are art, but what does that really mean? Art is an amorphous topic, and what one counts as art is largely subjective and not quantifiable, but there is a consistent theme to art in that it can be critiqued. By examining the language and critiquing it, one can therefore surmise that it carries meaning. The significant part of this is that the meaning that is within the conlang gives it some sort of relevance toward critique, and that critique gives it relevance in the world of art as a whole. The intersection between the history and the art of conlangs is also crucial to study for the reason that placing conlangs in an art history narrative gives it validity. If the premise of conlangs being art does prove true, then like any art form it can be historicized, which scholars have done before. But can it be placed into any sort of art trends? Literature has evolved over 
centuries to become what it is today, and went through various permutations to arrive at our current literary landscape, so what about languages? By examining conlangs from two different time periods, what will make them distinct? These are the areas of the literature I would like to develop a greater understanding of with this thesis.

\section{Methodology}

In this section, I go over my methodology of how I addressed the gaps of the literature with this thesis. This was done in two ways: the first was an interview with David J. Peterson, author of The Art of Language Invention (2015) and the second was a combined phonological analysis-close reading of two languages, Sindarin from Lord of the Rings (1991) by J.R.R. Tolkien and Kesh from Always Coming Home (1985) by Ursula K. Le Guin.

The interview with David J. Peterson asked questions regarding the creative process of working on a conlang, particularly in discerning the artistic and cultural aspects that are taken in account when creating a language for a larger world in a work. This was conducted over email, as that medium allows for a more nuanced answer than speaking over phone, and speaking in person would be unfeasible for this project. The reason why I wanted to interview Peterson is because it would fill in certain parts of the discourse around conlangs in the literature that are relatively untouched, considering its role as an art form and the role of the artist, or conlanger, in their creation. I believed this would also help support the second part of this thesis, the phonological analysis-close reading, in that understanding how the role of the author functions in the conlang creation can also help one understand how the background and literary styling of the author can affect how the language is expressed. 
The phonological analysis-evidenced close reading of Sindarin and Kesh was conducted by examining background information, utterances in the text, and their phonologies. The reason why phonology in particular is because examining the languages as a whole, including syntax, morphology, lexicon and their various other features would be far too ambitious for this project, especially considering that two are examined. Phonology itself is an interesting dimension of the language because it exists on a visceral level for listeners; whereas with syntax, one must pay close attention to the structural patterns inherent in the language, humans are trained by nature to listen closely to key sounds in speaking. That said, no one is listening to the texts, but rather reading them, so balancing sounds with orthography is itself a challenge. However, given that there are resources to know exactly how the speakers of the languages will pronounce each letter in the orthography, this should not be too difficult to surmise given a reader with all of the information at their disposal.

I first examined the background of the authors, and then their languages--the languages in two contexts --extra-textual, in how the languages came to be as pieces outside of the texts which they inhabit, and intertextual, in how the languages came to be and are used within the internal history and narrative of the text which they inhabit. This is because the languages are inseparable from these different contextual backdrops. The author's background is important as there is a piece of the author in each language, and learning their background may give some hints as to why the languages appear where they do; this is not to rely on authorial intent too heavily, but rather to use it to enhance what we can read from the text independent of perceived intent. The language's background is important because no language ever exists in a vacuum, both in the text and outside of the text. The reason why the history inside of the text is crucial is because the language needs speakers to exist in the first place and those speakers are made manifest by the 
events of the narrative, and outside of the text because of what has already been said about the author.

After investigating the background of the languages, I attempted to catalogue the contexts in which these languages appear and close read those utterances. This was to accomplish indexing the specific utterances and how they are used in the text, or generalized ways in which the language appears in the text. This is important for the reasons listed before, and also because these are languages that exist interconnected with the text, wholly in debt to these utterances for their very existences. Citing the places where the text appears is how it arrives to the reader, and this is crucial to the close reading element.

Using the utterances and their close readings above as a context to work off of, I then did a phonological analysis of the languages as they appear in the texts, and using some auxiliary texts on features of the languages not necessarily clear in the text, if necessary or available. This was carried through by summarizing the phonetic inventory and phonotactics of the language. These two elements are important to examine because they are critical dimensions of any language's phonology, and are useful for characterizing the language (Cheyne, 2008). Phonetic inventory for understanding the actual sounds available to the language and phonotactics for the identity of the language in how it is commonly expressed. These features were explicated, and then close read, as one would close read the utterances above. This is to surmise whether there is meaning in the language itself apart from the text, whether the language itself has some sense of artistic theme or bias. A typical phonological analysis of a language would be more in depth than just the phonetic inventory and phonotactics and would include elements such as allophony. However, since allophony is something very difficult to express in writing, and even the most discerning reader would find it difficult to accurate reproduce allophony in their own reading 
voice, I decided to exclude this from the process.

After this, I synthesized the close reading of the utterances and the close reading of the phonology. This is to answer the question, what can the utterances tell the reader about the phonological features, and what can the phonological features tell the reader about the utterances? This should support both of the readings at once, while also hopefully creating some sort of meaning from that point. By synthesizing both the close readings of the phonology and the utterances, it provides evidence toward the hypothesis that the languages themselves actually have meaning.

\section{Results}

\section{Part 1: Interview with David J. Peterson}

In this section, I recapitulate and explicate my interview with David J. Peterson on the experience of language construction and being a conlanger, and then use this information to understand how the artistic perspective of conlanging can inform the reading of a work that uses a conlang. Before moving on to the languages in the books, I sent questions to David J. Peterson in order to better understand what it is like for an author to create a language for an artistic purpose. Peterson is the author of The Art of Invented Languages (2015) as well as the developer of Dothraki for the television show Game of Thrones. Though based on a series of books written by George R.R. Martin, Dothraki had to be developed from a simple 'sketch' of a language, in that it was only a few words that seemingly made up a concept of what the language could be instead of an actual one, Peterson used those words to create actual conversational speech that could be used by the characters in the show. He also has developed numerous other languages for other speculative fiction properties, and works on his own conlangs as part of the greater 
conlanging community. In order to interview him, I first acquired IRB approval through the exemption process, which the reader can find in Appendix A of this paper, and the full email in Appendix B. I asked him a few questions, mostly aimed at understanding which parts of a language construction process are aesthetic and which parts are more deliberately chosen, using phonology and culture as a backdrop. In reply, he said "There is no connection between culture and phonology — period. Those that say there is are often simply speaking from a history of exoticism" (Appendix B). This outlines an interesting aspect as to how some artlangs can participate in a colonialist narrative, which were briefly looked at in the Sindarin analysis. Art works in that every art piece is a product of its artist, but every artist is a product of the society which they were molded in; the inherent biases, prejudices and injustices in that society carry on to the artist which carries on to the art, every piece acting as conduits for one another. Thus, even in the construction of a language, one can imprint the implicit biases present in one's society into the language itself. He continued:

When it comes to the sound of a particular root (because the roots are the only arbitrary parts of it), I sometimes do it based on what I want that word to sound like, or sometimes do it randomly. Sometimes I go against what I want it to sound like so my judgement doesn't color it. As long as it's phonologically and phonotactically licit, it can be a potential root in that language. This is purely for root creation, though. Very little else having to do with a language is arbitrary. (Appendix B)

This points to an intriguing facet of conlanging as an art form. One could say that art is largely defined by its arbitration: so much of art is dedicated toward subjective aesthetics, cultural relevance, and largely irrational taste. Not all art, however. Take realism, for instance, 
and its dedication toward creating a piece that successfully replicates, or at least emulates, the real world as people perceive it. However, the setting that is chosen to replicate is largely arbitrary: no paintings are painted because of a scientific rationality, but because certain people either are requested to by a benefactor, because it personally matters to them for whatever reason, or because it suits their particular aesthetic.

I also asked Peterson about what point a language becomes valid. Some constructed languages can be considered sketches, some are simply words on a page that have no bearing on each other. I wanted to know, is there a point where a constructed language can be considered finished in its development? Peterson had this to say:

A created language is never finished. Same as with a natural language. The only time it's finished is when the creator dies, but even then others can pick it up and use it and expand upon it if they want, and then it lives on in a different form, and continues to be unfinished. Instead, there are certain benchmarks one uses to evaluate the stages of a created language: When it can translate a simple text; when it can fill out a Swadesh list; when it can translate a longer text... It's a fuzzy boundary between a sketch and a full conlang. (Appendix B)

As background information, a Swadesh list is a selection of common words that exist in almost all languages, used typically for historical-comparative linguistics (Campbell, 1998). It was originally devised in 1952 but went through extensive redrafts until 1971 for a final list. The list includes words like 'I,' 'that,' 'big,' 'person,' 'dog,' and others that would normally exist in any other language. This is usually a routine point of progression for most constructed languages, as are the other points he brings up. To continue with the painting analogy, a sketch of a painting 
might not be accepted as a complete art project, but if the sketch is presented as a final art project, then the viewer accepts it as such. The same goes for artlangs: they have a more easy time becoming validated from conlangs, as they do not have to necessarily be conversational in order to still be recognized as a language, such as Dothraki, and to an extent the languages in the analyses. The authors use these conlangs as they appear in the text to communicate that this is the language the characters are using, it is a different language from anything they have ever seen before, and they probably do not understand it as a result. This is where artlangs move language away from the utilitarian aspect to a more abstract and aesthetic aspect. Whereas a language like Esperanto has to do much more than just translate a simple text to be accepted for its purpose, a language like Dothraki need only have a few words with a recurring meaning in order to be accepted for its own purposes, as those few words can still communicate a great amount of feeling and tension to the reader without them necessarily needing to know what they say.

When talking to Peterson about the shows he has worked on, such as Game of Thrones and Defiance, I asked him to what point he was familiar with the culture before he started work on the language. Specifically asking him about where he knew the culture at all before working, he said:

That's certainly been the case for all the shows I worked on. I'm brought in at a point where the speakers have already been defined. As I flesh out the vocabulary, though, I help to flesh out the culture as well. This happens naturally in the course of vocabulary creation. (Appendix B) 
This is another unique facet of language creation, in deciding what parts will develop the culture, and actually being able to help develop a culture by shaping how it is represented in the language. Though culture is unrelated to phonology, it is present in many other details of a linguistic system, one of which is ethnosyntax (Enfield, 2002), which is the relation between how people form words and sentences and how that can sometimes be indicative of cultural touchstones. Another is vocabulary, as Peterson said, because the vocabulary which the culture develops needs to be related with what they encounter in their everyday lives, which is largely shaped by culture. For Dothraki, it is a largely horse-centric nomadic society with a warrior culture, so it makes sense that Dothraki would have many different words for specific ways to strike someone while riding a mount. This is part of what makes art language creation somewhat less arbitrary and aesthetic-based than other art pieces, in that the language is, in part, dependent on the culture that it is created to represent. But that said, the culture itself is largely going to be based on the aesthetics of the author, and through that, their aesthetics are replicated within the language. As Peterson is both a prominent conlanger (he is the president of the Language Creation Society) as well as a trained linguist with an M.A. from UC San Diego, it was refreshing to have some of the information about conlangs elaborated on from an authorial point of view.

\section{Part 2: Sindarin}

In this section, I analyze the language of Sindarin as it is portrayed in The Lord of the Rings. To begin, I go over the background information of Sindarin both extratextual and intertextual, by conveying the history of J.R.R. Tolkien and his developmental process of the languages, the history of the language in the background of The Lord of the Rings, and the instances in the book 
where it is uttered. After this, I move on to phonological analysis of Sindarin, drawing resources from many authors who have sought to create a very complete grammar of the language already, in a more summarized and brief fashion. Following the phonological analysis, I go into how the language, its appearances in the book and its phonology are informative of Tolkien as an author and Lord of the Rings as a landmark book in the canon of modernist literature.

In the Silmarillion (1977), the history of Eä is chronicled. This is the universe in which The Lord of the Rings is set, the vast world where Middle-earth resides along with various other lands celestial and terrestrial, a universe not so unlike our own. There are flourishing and suffering peoples, songs and poetry, fractured histories which become lost to time and turn to mere myth. The most distinct difference between Eä and our world is that, in Eä, all of those myths actually happened. In it, the world was created due to the singing of supernatural beings: their theme, harmony and discord formed the world from thought, including all the lands, the seas and the peoples. The first of those people to awake were the Elves. They exist in such a young universe that the sun and moon have not even formed, surrounding them a boundless forest, and above them a blanket of infinite stars. As they awake, the distant starlight enchants them, and they speak their first utterance: Ele! Or, in English, 'Behold!'

In that tale, ele! was spoken to acknowledge existence. But it may be more accurate to describe Middle-earth, The Lord of the Rings and Eä to be created in order for ele to be spoken. J.R.R. Tolkien lived a life marked by tragedy: he was orphaned, was enlisted in World War One, and watched many of his friends tragically and violently die (Lee, 2014). But he always escaped to language and poetry. He fell in love with languages like Welsh and Finnish and would create languages emulating them. He not only created languages, but also entire language families, 
dialects, historical languages, primitive languages, dead languages. Other authors created small snippets of language for their fictions, but "the first widely known author to use a more or less fully constructed language was J.R.R. Tolkien, who set the bar very high” (Peterson, 2015, 10). He was more or less a language creator before he was an author, but understood that his languages could not simply exist in a vacuum. They had to exist in some sort of tangible way, a way to explain why certain languages existed, why certain features developed, why they were spoken by what people. From this, he developed Middle-earth, which allowed his languages to breathe. He is quoted as saying "Nobody believes me when I say that my long book [The Lord of the Rings] is an attempt to create a world in which a form of language agreeable to my personal aesthetic might seem real. But it is true" (Okrent, 2009, 283).

In a way, Sindarin is the final evolution of these languages. The first Tolkien created was Quenya, which was also the first language spoken in Eä (ele is Quenya, for instance). Both Sindarin and Quenya are Elvish languages, but Sindarin split from Quenya long before the events of The Lord of the Rings (Salo, 2004). In the mythos of Middle-earth, when the Elves first awoke, they all spoke Quenya, which they themselves created out of will. But when some of the Elves were beckoned by the supernatural Valar to travel West, some Elves answered the call, and other refused and stayed behind. The Elves who traveled kept Quenya and were known as the Eldar, or 'people of the journey,' while the Elves that stayed behind were known as the Sindar. The Eldar were later dubbed 'High Elves' while the Sindar are referred to as 'Grey Elves,' which marks a certain social distinction. When the Eldar returned from their journey to the West, Quenya was relatively unchanged, whereas Sindarin had developed over the course of hundreds of years into a completely different language, with speakers of either being unable to comprehend one another. The Eldar eventually adopted Sindarin as a common language to 
communicate between the two groups, but kept Quenya as a language of poetry, song and law. One could see this as somewhat analogous to the relationship between Latin and French, or French and English, in the medieval period of Europe. Sindarin itself is based on Celtic and Welsh grammar, with Quenya being inspired mostly from Finnish.

The first instance of Sindarin in Lord of the Rings is indicative of a saving grace, a theme which occurs multiple times through its inclusion in the book, as every time Sindarin is uttered, it usually comes with an external force coming to rescue the protagonists from imminent harm. In the chapter "Flight to the Ford," the group from the Shire is being pursued by the dreaded forces of Sauron, the Nazgul. Frodo has been pierced in the chest by a poisoned blade, and is slowly but steadily dying as the band tries to flee to Rivendell. As they hide in the thicket off the road, they hear a horse clopping down the road, and initially believe it to be the sound of the mount of one of the Nazgul. But as it draws closer, the steps of the steed sound musical, and "they seemed to catch a dim ringing, as of small bells tinkling" (1991, Tolkien, 204). This is an important entry into the language, as the reader is already shown how sound can communicate a sense of friendliness and hope. Frodo gets a glimpse of the rider, and he almost appears to him as a shining light on horseback, seen as a savior. This rider is Glorfindel, who came to rescue them from the Nazgul. His first words are not in English, but he instead speaks to Strider, who is fluent in Sindarin, crying "Ai na vedui Dunadan! Mae govannen!" meaning 'Oh at last, Westman! Thou art well met!' $(1991,204)$. The utterance itself and the way the utterance is spoken communicates a tonal shift in this part of the text. Sindarin is meant to be communicated as a friendly language, and the utterance itself translated is friendly (in this edition of the book, the utterance is not translated — but a reader familiar with the language already would be able to translate it easily). After this instance, the titular ford is reached, with Frodo being carried on the 
back of Glorfindel's steed as they are closely pursued by the Nazgul. With Glorfindel on one side of the bank and the Nazgul on the other, Glorfindel makes this urrerance: "noro lim, noro lim, Asfaloth!" meaning "Run fast, Asfaloth, run fast!" $(1991,208)$. Seemingly, nothing happens, and the Nazgul approach closer, stepping into the bank, closing the distance on to their prey. But the ford begins to splash and foam, the waters become restless, and Frodo sees "amid the water white riders upon white horses with frothing manes" $(1991,209)$. Glorfindel, using his speech, summoned a powerful, and literal, wave of riders down the flood, careening into the Nazgul and wiping them away. In this instance, the saving grace of the language in the previous utterance becomes near messiah like now: the speaking of the words appears to manifest into miracle, allowing Frodo to escape alive from what was certain death.

The next time the reader comes into contact with a Sindarin utterance is in the chapter "A Journey in the Dark," in two different contexts, both spoken by Gandalf. The first is very similar to Glorfindel's "noro lim" spell, as Gandalf uses Sindarin to summon fire in order to save the Fellowship from a pack of wargs. "Naur an edraith amen! Naur dan I ngaurhoth!" $(1991,291)$ he cries, meaning 'Fire save us! Fire against the werewolf-host!' Functionally, this reminds the reader of the mystical power of Sindarin and the Elves. It is important to note that magic and miracle manifest directly through language in this sense, but that becomes complicated in the next utterance later in the chapter, when the Fellowship comes across the sealed gate to the Dwarvish city of Moria. Gandalf, speaking again, attempts to open the entrance with another spell: “Annon edhellen, edro hi amen! Fennas nogothrim, lasto beth lammen!” (1991, 299). This utterance translates as "Elvish gate, open now for us! Dwarven doorway, listen to the word of my tongue!" However, this spell does nothing to the door. Though the reader may be used to Sindarin being a word that creates magic upon its very speaking, this call is answered by mere 
silence. Eventually the door is opened with a simple Dwarvish word, but what this part conveys to the reader is that Elvish, although it can be used for mystical means, is just one language that exists in a magical world.

The last time the reader sees an utterance of Sindarin is at the end of the chapter "Lothlorien," in which Frodo finds Aragorn at the foot of a hill, holding a golden flower, speaking these words: “Arwen vanimelda, namárië!” (1991, 343) The translation approximates to 'Beautiful Arwen, Farewell!' This references the romantic tale between Aragorn and Arwen, which is referenced in poetry outside of the book. After saying this, Aragorn tells Frodo "Here is the heart of Elvendom on earth... and here my heart dwells ever, unless there be a light beyond the dark roads that we still must tread, you and I. Come with me!"' $(1991,343)$ This acts as a melancholic moment in a way that is both explicit and unrevealed to the reader: explicitly, in that this is described as the last time Aragorn visits this place as "a living man," and hidden in that this is the last of Sindarin they read in the novel, as the Elves will eventually depart Middle-earth forever. It is melancholic, but beautiful all the same. It tells a story of love without needing to impart it completely to the reader, in words they do not necessarily have to know to understand the meaning.

Using these instances of Sindarin from Lord of the Rings, as well as a David Salo's A Gateway to Sindarin (2004), I use this section to explicate the phonology of Sindarin. Although it may seem odd to deviate from the source material for analyzing a fictional language, Salo is an authority on the manner as he was one of the main developers for Sindarin for the film adaptations of Lord of the Rings, and has done an extensive amount of work in documenting and expanding Sindarin from what could roughly be considered a language 'sketch' to a fully conversational tongue. This 
is actually a fairly common practice in artlangs, particularly for adapting conlangs from works of literature into television or film. Despite being developed fully by another author, the language still follows the same rules as well as the same 'idea.' The idea, in this case, is that Sindarin is to follow a largely Welsh phonology, which is demonstrated in the sound inventory in Figures 1 and 2. There are a few exceptions between Welsh and Sindarin, however, in that Sindarin has no

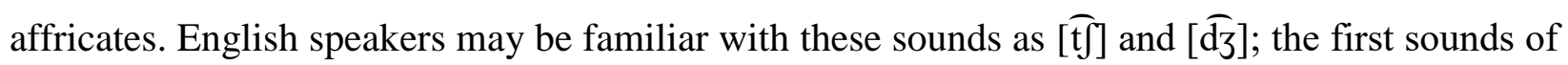
"chuck" and "jump," respectively. There are also considerably less vowels in Sindarin than in Welsh (Jones, 1984). There may be an aesthetic point to both of these exceptions; as mentioned earlier, Sindarin is “a form of language agreeable to [Tolkien's] personal aesthetic," (Okrent, 2009, 283) and many of its features are likely the desire to capture the feeling behind the Welsh names Tolkien saw as a child, rather than capturing an exact accurate replica of what Welsh actually is phonologically. In the book, Sindarin shows up in two contexts. The first is amicability and familiarity, with the two examples being Glorfindel greeting Aragorn (the first time the reader sees the language) and Aragorn reminiscing of Arwen. The second is spell casting, with the examples being Glorfindel summoning the raging waters of the river to destroy the pursuing Nazgul, Gandalf causing wargs to alight so that the Fellowship may escape, and Gandalf failing to open the door to Moria. Aside from this failing instance, the spell casting instances are always intrinsically tied to saving the protagonists from dire harm. This makes even the spells amicable in nature - so the two contexts are inseparable. The way this ties back to the sound inventory is that the language is meant to sound both amicable and magical. One can see the consonantal sound inventory in the table below, figure 1. In the excerpts, one can see a predominance of liquids and nasals, many $/ \mathrm{r} / \mathrm{s}, / / \mathrm{s}$ and $/ \mathrm{n} / \mathrm{s}$. To Tolkien, and likely to many Anglophones, this is what may sound the most amicable in nature. Though it likely is not the same for speakers of all languages, since taste in sound is 
largely culture-specific, affricates can sound somewhat harsher than liquids or nasals. Affricates are an inherent mash of a plosive and a fricative, beginning with a [t] and following with a [J]. They have an inherent interruption, which could be interpreted as discord. In contrast, liquids and nasals are largely used for sounds of music: la la la is the stereotypical mode for singing when one forgot the lyrics to the carpool song, and if one simply is not comfortable opening their mouth at all, they will resort to the humble hum, hmmm. As for the vowels, this may also be a cultural choice. The vowels are documented in the table below, Figure 2. There are a few dipthongs in the language, $a i$ [ai], $e i$ [عi], $u i$ [ui], and $a u$ [au], but even with those included it still is a meager number of vowels compared to Welsh, which contains a great deal more; 20 compared to Sindarin's 8 (Jones, 1984). This is excluding long vowels, which are in both languages but the usage is not completely clear in Sindarin. What does this do for the text? For one, the reader is able to follow along easily if they do not have to grapple with constantly changing vowels, creating a sense of rhyme and rhythm. Take noro lim, noro lim for instance. In terms of vowels, it is very easy for a reader to repeat that in their head, as it is simply o o $i$ o o $i$. One could equate it to a song with two tones. That is part of the familiarity that is brought in the context: the reader needs to be able to be friendly with Glorfindel as soon as they approach him, and by speaking in a simple to follow manner, it becomes less frightening to confront. Hearing a new language is always curious, and in certain contexts it can be terrifying. But if the language is easy to follow, even if one does not understand the words, they can immediately become familiar with the sounds. The complication to this notion, however, is that the language contains a few sounds that are rare for anglophones to encounter, as well as most speakers of European languages. This is mostly characterized by the voiceless alveolar fricative [ [] and the voiceless liquid of $[\mathrm{r}]$. This may be to exoticize the language for the reader, which is a key point later on. 


\begin{tabular}{|c|c|c|c|c|c|c|}
\hline & Bilabial & Dental & Alveolar & Palatal & Velar & Glottal \\
\hline Plosive & $\mathrm{pb}$ & & $\mathrm{td}$ & & $\mathrm{kg}$ & \\
\hline Nasal & $\mathrm{m}$ & & $\mathrm{n}$ & & $\eta$ & \\
\hline Fricative & f v & $\theta$ ð & s 1 & & $\mathrm{x}$ & $\mathrm{h}$ \\
\hline Trill & & & $\mathrm{rr}$ & & & \\
\hline Approximant & & & 1 & $\mathrm{j}$ & $M W$ & \\
\hline
\end{tabular}

Figure 1: the consonantal phonetic inventory of Sindarin.

\begin{tabular}{|l|l|l|l|l|}
\hline & Front & Near Front & Near Back & Back \\
\hline Close & i y & & & u \\
\hline Near Close & & I & v & \\
\hline Open Mid & $\varepsilon$ & & & 0 \\
\hline Open & a & & & \\
\hline
\end{tabular}

Figure 2: the vowel phonetic inventory of Sindarin.

If the phonotactics are what give a language a sense of identity to the outsider, then what is the identity that Sindarin is hoping to project? There are several rules dictating the 
phonotactics of Sindarin, with some of the main ones being thus: for one, every syllable must contain a vocalic core and attached consonants. The most complex form of a syllable is CCVCC, meaning that there can be no consonant clusters larger than 2 consonants at a time. In addition, there cannot be four consonants next to each other, even if they are part of two different syllables, in a single word. The with idhren appears to have three consonants, but it is split in this way: idh-ren. A word like idh-gren, however, could not exist within Sindarin. If a consonant cluster begins a syllable, then the second consonant must be $l, r$, or $w$. This means clusters such as $s t$ or $s p$ cannot exist in the language, only clusters like $s l$, or $g w$ or $b r$. This is in line with Welsh phonotactics, which is limited to three element consonant clusters for word initial and two consonant clusters for word final (Jones, 1984). With the phonetic inventory, I mentioned that there are certain sounds meant to exoticize the language, but this simple consonantal form does the opposite in some ways by actually making the language easier to follow along. Therein lies the complex nature of the Lord of the Rings' construction and implementation of languages. Certain languages with certain amounts of exoticism are amounted to be 'good,' such as Sindarin and Quenya, and that is largely expressed through the phonetic inventory and the phonotactics. But in other languages, such as Dwarvish or the Black Speech of Mordor, it employs exoticism in such a way that it becomes negative. According to Michael Adams, while Sindarin and Quenya are respectively inspired by Welsh and Finnish, Dwarvish and Black Speech are representative largely of a Semitic root, which is traced to languages such as Hebrew and Arabic (2011). In a way, this betrays a colonialist bias against the languages. The context fits: Tolkien, after all, was raised in England, which had a hand in the Sykes-Picot agreement which divided the Middle East into the nations it largely is today, which began the colonial subjugation of Arab people by Western powers (Makdisi, 1995). This is not to say that Lord of the Rings is colonialist 
literature (that would be a different paper altogether), but the languages themselves and the way they are presented is indicative of the cultural signifiers of the era. As the United Kingdom is colonialist in nature, particularly for the era in which Tolkien was creating his languages (after World War I) the culture represented through the languages must be colonialist itself in nature; the same for most art products produced in most colonialist nations.

But this leads me to my larger point: the languages themselves are the art. Sindarin is an art piece, as much as Lord of the Rings is an art piece, and the idea of creating a narrative in order to fit around the languages fits incredibly well with the modernist period. Take As I Lay Dying (1930) by William Faulkner as a case example of a seminal modernist work. Much of its power in complicating the classical narrative is the way that it is told, by shifting perspectives between fifteen different characters, all who speak, think, and act distinctly from one another, which changes the way the story is perceived. This is a key aspect of modernist literature: the realization, after World War One, that the traditional narrative simply could not tell the stories that needed to be told aptly enough. In As I Lay Dying, the story is defined not by the events that occur, but how the events are told: using incomplete thoughts, stream-of-consciousness, even transcribing the dialects of the characters. Using these techniques, it creates a story unlike any other told before its time. Tolkien, granted to a lesser extent, employs this same mode of philosophy in another way. Although he tells a classical narrative, which some scholars have noted to be a reaction to modernist literature (Mortimer, 2005), the narrative itself is not the art that should be examined, but the languages and the world he develops around the narrative. The languages and the world are the more intriguing and significant aspects of Lord of the Rings, after all, and although its narrative has inspired little in terms of modern fiction, its novel setting and languages have carried through the test of time, as can be seen with many contemporary 
fantasy novels emulating Tolkien's work: the roleplaying game Dungeons \& Dragons is a critical example. In terms of timeline, most modernist writings came directly after World War I or a decade or so afterwards, and Lord of the Rings arrived relatively later in the process, having started writing around 1937 and actually being published between 1954 and 1955 . However, Tolkien actually started to develop Quenya and the Middle-earth world as soon as the Great War broke out (Okrent, 2009) and developed it after that period of time. In this sense, the Lord of the Rings may not fit the timeline exactly, but the languages do. I posit that the development of a family of languages, the development of a universe of fictional peoples and places, is in line with modernist philosophy because it is founded on the recognition that what previous assumptions about the world cannot tell the stories that must be told. Tolkien needed to tell a story, and he could not use the history that was already accessible in order to write them. He needed to give the stories life and language, but could not do it with languages that existed already. For this, he made a monumental effort to create a world that no one had ever done before, through the creation of a language family and the creation of an entire world history. Through this, it falls in line with the modernist philosophy of art, and I argue that it raises important implications for understanding conlangs themselves as art forms, with their own history, their own social importance, and their own unique validity.

\section{Part 3: Kesh}

In this section, I analyze Kesh similarly to Sindarin. However, as Kesh is not as developed of a language as Sindarin, this section does not document as much of the language as the Sindarin section. I first give background on Ursula K. Le Guin and her impact on the speculative fiction canon, then give background on Kesh as it appears in Always Coming Home 
(1985), the only work of her bibliography in which it appears. Then I move on to describing the phonetic inventory and the phonotactics and spend some time along the way describing how Le Guin differs from Tolkien both in how she utilizes the language of Kesh and how the language itself is developed. As a side note, this section is a good deal shorter than the section on Sindarin, as Kesh is not quite as largely developed as Sindarin, and on account of it appearing in less instances throughout the text of Always Coming Home.

Ursula K. Le Guin was arguably the most influential science fiction author of the latter half of the 20th century. Through her writing career, she published numerous bestsellers, and won the Hugo Award, the Nebula Award, the Locus Award, and World Fantasy Award several times over for each one (Timberg, 2009). She influenced many speculative fiction authors, as well as Booker Prize winners, like Salman Rushdie. Most of her work dealt with confronting inequalities and injustices perpetuated under capitalism and patriarchy through the lens of speculative fiction, using imagined worlds in order to explore radical possibilities of change. One of such works is The Left Hand of Darkness (1969), which is set on a world in which humans have developed to be hermaphroditic, acquiring or losing female or male sexual organs throughout different periods of their lives, acting as an important work in subverting how gender can be represented in speculative fiction works. One of her most successful works, The Dispossessed (1974) focuses on an anarchist society caught between the tensions of two planets which represent capitalist and communist philosophies. This story is especially interesting as this anarchist society created a language, Pravic, which syntactically made it impossible for speakers of the language to refer to certain hierarchical terms. For instance, there were no singular possessive pronouns and there were no words for words like prisoner or master. However, Pravic is essentially a 'sketch' of a language and has a very limited linguistic makeup. The 
phonology seems particularly underdeveloped, and there is a somewhat short lexicon. But this is what fits for the literary work, more or less; Pravic did not have to be a complex language, with a sound system, with a large lexicon, it only needed to be a sketch (as Peterson puts it) to communicate to the reader what Pravic-speakers valued, what their culture represented, and the way their anarchy manifested through language. The Dispossessed is largely considered to be her magnum opus (Call, 2007) and along with The Left Hand of Darkness and The Lathe of Heaven is more popular than Always Coming Home by an order of magnitude. One could consider Always Coming Home to be a bit of a 'sleeper hit,' which is almost shocking. It is an incredibly ambitious work. The narrative revolves around a future culture, the Kesh; the book's foreword describes the situation as "the people in this book might be going to have lived a long, long time from now in Northern California," (Le Guin, 1985, xi). The culture and society of the Kesh are relayed to the reader in a multivalency of forms: Always Coming Home is a traditional narrative driven story told from the perspective of a Kesh woman given the name of Stone Telling, but it is also a ethnographic report from an outside observer called Pandora, and the rest of the book is filled out with dozens of songs, poems and folktales from the Kesh people. The book even comes with a CD of Kesh music. It is a large scale project of creating a fictional group of people with a fictional language.

The history of the Kesh is largely unknown, an intentional act on the part of the author. The sections which are narrated by Pandora delve into the mysteries of history keeping and archiving. The period in which the book is told appears to be far in the future, but largely anachronistic. The Kesh use guns, trains, electricity, and a large computer network for archiving, but are also a hunter-gatherer society with some agrarian elements, commune with nature, and use adobe building materials. The time period is not made explicitly clear, but the Kesh have 
existed for at least 500 years $(1985,314)$ and according to a map of the region, the Central Valley of California appears to be flooded $(1985,140)$, a common projection of what extreme rising sea levels would manifest as. But the history remains murky, unclear and largely unknown. The Kesh even destroy books in their library every few years, clearing away old information in order to bring in the new. Pandora questions the Kesh Archivist about this conundrum and their reluctance for information, and they answer, "books no one reads go; books people read go after a while. But they all go. Books are mortal. They die. A book is an act; it takes place in time, not just in space. It is not information, but relation" $(1985,315)$. The rejection of history may communicate much about the anachronistic nature of the Kesh; they do not fit within any period of time. They have a complex computer information network, but they do not utilize it. They have electricity and trains, but often prefer to ride on horseback. They have all the information in the world to learn about healthcare, but they choose instead to have a high infant mortality rate, allowing them to live off of the land instead of expanding rapidly. Their culture appears to simultaneously criticize and romanticize anarcho-primitivism. In a fourth-wall breaking moment, the Archivist says to Pandora:

This is a mere dream dreamed in a bad time, an Up Yours to the people who ride snowmobiles, make nuclear weapons, and run prison camps by a middle-aged housewife, a critique of civilization possible only to the civilized, an affirmation pretending to be a rejection, a glass of milk for the soul ulcered by acid rain, a piece of pacifist jeanjacquerie, and a cannibal dance among the savages in the ungodly garden of the farthest West. $(1985,316)$ 
Unlike The Lord of the Rings, Always Coming Home does not contain a specific amount of Kesh utterances. Rather, Kesh lexemes are used frequently throughout the text, occurring once every couple of pages when communicating a word that is culturally important to the Kesh. The most common word used is 'wakwa' which translates to many different meanings depending on its context. It can either mean 'spring' or 'source of water,' or it can mean a 'ceremony,' a 'dance' or 'mystery' and can either occur as a verb or noun. Another important word is 'heyiya,' meaning 'sacred thing (or time, place, event),' 'connection,' 'hinge,' 'center,' 'change,' 'praise.' The interesting aspect of 'heyiya' is that there is not really something that can be considered 'sacred' in a theological sense; in fact, the Kesh do not possess a true theology, but rather a cultural understanding of the balance of life — more align with Taoism than Christianity— and this understanding is represented through a series of metaphors. There are multiple 'houses,' some of which belong to the earth and some belong to the sky, some belong to the living and some to the dead. None of this is taken as literal, but rather as just a metaphor. And yet they still use the word 'heyiya' for many instances, often referring to what they consider to be sacred. This may relate much to Le Guin's thematic critique of normative social constructs, including religion.

Despite the lack of utterances in the text, the book also has a large amount of appendices, which include the orthography of the language with associated phones, and a list of lexemes. These phones have been organized into the two tables below, IPA phonetic inventories of the consonants (figure 3) and the vowels (figure 4). Unlike Sindarin, the phonology appears to have no clear relationship or inspiration to any existing languages, and seems to act almost intentionally as a departure to English given the phonetic inventory. There are many sounds which are uniquely distinct from English's phonetic inventory. Take, for instance, the 
multiplicity of alveolar trills, none of which English speakers use commonly, but the lack of the retroflex liquid that is used whenever anglophones use /r/. In addition is the [1], also unused in English (one will remember this being used in Sindarin), as well as the voiceless dental plosive with lenition $[\dot{\mathfrak{t}}]$, but no voiceless dental plosive without lenition $[\mathrm{t}]$.

\begin{tabular}{|c|c|c|c|c|c|c|c|}
\hline & Bilabial & Labiodental & Dental & Alveolar & $\begin{array}{l}\text { Postalve } \\
\text { olar }\end{array}$ & Velar & Glottal \\
\hline Plosive & $\mathrm{pb}$ & & $\mathrm{d} \dot{\mathrm{d} \dot{\mathrm{t}}}$ & & & $\mathrm{kg}$ & \\
\hline Nasal & $\mathrm{m}$ & & & $\mathrm{n}$ & & & \\
\hline Trill & & & & $\tilde{\mathrm{r}} \mathrm{r}$ & & & \\
\hline Fricative & & $f_{v}$ & д & $\mathrm{s}$ & $\int$ & & $\mathrm{h}$ \\
\hline $\begin{array}{l}\text { Lateral } \\
\text { Fricative }\end{array}$ & & & & 1 & & & \\
\hline Approximant & & & & & & W & \\
\hline $\begin{array}{l}\text { Lateral } \\
\text { Approximant }\end{array}$ & & & & 1 & & & \\
\hline
\end{tabular}

Figure 3: The consonantal phonetic inventory of Kesh.

In contrast, the vowels are very similar to American English, with the exception of [y], which is still used commonly in languages like French. It appears that the consonants and vowels 
are a bit at odds with each other in terms of inventory and departure from English. If this is a future Northern California, set several hundred years from the future, would there not be a vowel shift in any of that time? It creates an interesting quandary into what the Kesh developed from, and how, and where they began to use the different consonantal phones. In a way, the language is largely defined by being unrelated to English despite evolving in California, but it contains many similar sounds. The diphthongs include [ow], [ai], [عy] and [əy]; Le Guin makes the note that the last two diphthongs are not actually represented in the orthography of the Kesh, "for no reason anybody could cite," $(1985,497)$. This, for one, problematizes the documentation process as the orthography which I am acquiring used phonemes might not include all of the phonemes available.

\begin{tabular}{|l|l|l|l|l|}
\hline & Front & Near Front & Near Back & Back \\
\hline Close & i y & & & u \\
\hline Near Close & & I & & o \\
\hline Open Mid & $\varepsilon$ & & & 0 \\
\hline Open & a $\Lambda$ & & \\
\hline
\end{tabular}

Figure 4: The vowel phonetic inventory of Kesh.

The phonotactics were analyzed by looking for phonotactic patterns in the lexical list. The trend was that every syllable is represented by a vowel nucleus, and can be preceded by up to two consonants in a cluster, but only one consonant as the coda. If there is a consonant cluster, the second consonant must be either $/ \mathrm{h} /$ or $/ \mathrm{w} /$. The final syllable of a word is typically a vowel, 
but it could also be a nasal $/ \mathrm{n} /$ or $/ \mathrm{m} /$, a plosive $/ \mathrm{d} /, / \mathrm{t} /, / \mathrm{k} /$ or $/ \mathrm{p} /$, or very rarely a fricative, only [J] or [v]. It is interesting to note that $/ \mathrm{d} /$ is the only voiced plosive which can end a word. The consonantal-vowel pattern, then, is CCVC at its most complicated, but will usually be presented as just CV. Once again, this is a good deal different from English in terms of phonology, and it may be interesting to speculate the conditions of what this could have arisen from. The first is that Always Coming Home is set a great deal of time in the future; much longer than 500 years, maybe even much longer than 1000, to the point where any English root is abandoned. The second is that English was abandoned as the dominant language of California, and was not taken up by Spanish, as it is phonologically disparate as well. The third, and the most intriguing to me, is that Kesh is an invented language. The society of the Kesh appears to be almost planned in execution; they have abandoned many staples of modern living in order to adopt a huntergatherer lifestyle. They reject advanced healthcare, but accept certain connections to technology, through the 'Exchange,' the massive computer network which archives their history, a train line which runs across California, and guns which they will occasionally go to war with. Even the war seems to be starkly more civilized than it is to us, and 'civilized war' might as well be an oxymoron. The various groups the Kesh interact with, such as the 'pig people,' (they are not actually pigs, they are simply people who rely on pigs for agriculture) engage in war by agreeing to it on a specific date at a specific place — one could call it honorable. However, this may be the text waxing the idealism of the reader without having them interrogate the root issue, that war still exists and there is still a collective murder between societies, no matter how polite it may be. Just as the archivist said, this is "an affirmation pretending to be a rejection," or the opposite. If these crucial elements have almost been selectively chosen and engineered to create a sustainable society, why would the language not be? The issue here is that the history simply is not there- 
no one knows where the language developed, what it developed from, or why it developed in the first place. In a way, it is almost as though the reader is being told to ignore everything around them except for the Kesh. The reader is not told what goes on outside of Northern California, they do not even know if it is a California they can recognize the landscape of. The same thing remains for the language. The reader cannot recognize it, and in that way, it exists in a vacuum.

It is interesting to note the relationship between this language and Sindarin in terms of exoticism. For one, Le Guin has always been consistently anti-colonialist in her books, and the language itself may represent part of that inspiration. One can see this as a part of her own postmodern background. If one accepts Tolkien to be a modernist author, one can also in turn see Le Guin very much as a postmodern author. Lewis Call writes about Le Guin's most major works from the point of postmodernism, describing Left Hand of Darkness in particular as a "postmodern masterpiece," in that it has no true narrative center and jumps between many different viewpoints and timeframes. The same can be seen with Always Coming Home - the book is told from the perspective of an anthropologist's ethnography, a Kesh woman's story, and a large collection of Kesh poems and songs. All of these represent the Kesh, but it shows that no seeing of the Kesh is incomplete without multiple perspectives - for one, it shows an outsider's ethnographic perspective as not the primary narrative, but Stone Telling's. This is in contrast to many colonialist works, in which the exotic is only represented from an outsider narrative. Sindarin, for instance, is only seen from the perspective of Frodo, or Aragorn, who the reader is supposed to relate to the most as the most conventionally modern characters. In Always Coming Home, the ethnography is incomplete without the representations of the culture. This cements the book as a postmodernist, postcolonial work, compared to Lord of the Rings which is modernist and colonial—but is Kesh suitably postmodern? One can say that Kesh does not do anything 
particularly spectacular in terms of its language construction, and in fact is somewhat less complete of a language than Sindarin. It is more of a 'sketch' than a full language that can be spoken conversationally, and its purpose in the book (with its orthography and lexical library included) is to round out the Kesh and make them more believable as a culture that could actually exist many years from now. The addition of the language to create a more rounded out culture, to see the culture from a perspective beyond that of the outsider, and to expand what the reader can consider to be a "truthful" narrative may be postmodern, just as Tolkien creating a language in order to better tell his story can be considered modern. But it is difficult to consider whether the languages themselves are modern or postmodern. As stated before with Peterson's interview, language creation is largely a very non-arbitrary process, with the only really arbitrary aspects of the phonology being in the root creation. With Kesh, it is difficult to figure out what the root actually is, since the history has been destroyed, the root itself lost to void. Sindarin had a long history, recorded and documented, and the reader can find it easily in the Silmarillion or other texts by Tolkien or those who continued his legacy, such as David Salo. This was a very realistic process, and one could say it falls into a 'realism' movement of language creation, but Kesh is simply too incomplete to know. There could be something more to it - a background the reader may never know, a phonology that could complicate Kesh as a language and Always Coming Home as a text that will never be revealed.

However, one can, and should, still consider Kesh valid as an analyzable text. Ria Cheyne notes this in her own breakdown of the artlangs in science fiction:

Real-world constructed languages are designed to be used for human communication. They need to be extensively developed, with a large vocabulary, comprehensive grammar 
rules, and so on. The created languages of science fiction, in contrast, do not serve the purposes of practical communication. (Cheyne, 2008, 389)

Though conlangs in speculative fiction do not communicate in a practical sense, they still communicate meaning to the reader simply by their inclusion in the text. The 'meaning,' in this case, is the truth of the text—what the text is trying to communicate to the reader, the ambiguities it is revealing, the multiplicitous truth. Language may be a tool, but it is also an art, and it is an art that can never be completed. Kesh may not be completed yet. Another author may come and develop Kesh to another benchmark, and at that point what does it become? What does it do to Always Coming Home? Perhaps readers will perceive it differently, and that perception will change the work to an absolute extent.

\section{Conclusion}

In this thesis, I have attempted to use the phonologies of Kesh and Sindarin in order to analyze the text through the languages, and analyze the languages themselves as valid art forms. Through this, I have discovered that languages help uplift the literature in their own right, languages themselves can be considered as art forms, and that phonology is not a necessarily clear or easy aspect to utilize when analyzing the texts.

Language is an act of mutual trust. All of us experience, learn, and understand language uniquely yet dependently on one another. All humans are capable of language, but only together is it applicable. It is the greatest tool humanity possesses, the most harmful weapon, an act we make that will change with every utterance. It has been said before in this paper, but it is an important thing to emphasize: creating a language is a monumental task, and it involves grappling with what it means to be human. To implement this into a text is to understand the 
humanity of the characters who speak it, to understand the greater cultural understanding that lives and breathes within the text. Like an ant creating its own colony from nothing, it is like taking the metahuman phenomenon of emergence and attempting to replicate it as human. These languages are crucial to the texts, and they would be very different if they were not included. The Lord of the Rings would not exist if it were not for the languages—-Kesh would not be a complete culture if it were not for its language.

The Whorfian hypothesis is not proven in the real world - it may never be proven one way or another, and the idea of linguistic relativity is very subjective and fluid as it is. But there is something to be said about linguistic relativity in the realm of speculative fiction. The cultures themselves can be shaped from the languages. Take Sindarin, and its music-like phonology. The Elves would likely not be who they were if it were not for the language which Tolkien developed for them. Their conception as a people arrived after the conception of the language. The same could go for the Kesh: their nature of destroying the past, their anachronism, can be seen as divulging from the mysterious origins of the language of Kesh itself. This could not be replicated in the real world, as the people always arrive before the language does. Language is a product of people, people are not a product of it. But in literature, the fictional people may be the product of a fictional language.

The languages themselves can be considered art forms, but it is still unclear to see where they will go as an art form in the future. As of now, constructed languages still draw greatly from the pool of resources which we know today. Natural languages largely form the pool from which they are drawn, no matter how far they deviate from their birth. What does it mean for a language to be modern, or postmodern? What does it mean for a language to be abstract? These are questions that may be answered far from now, but it will be interesting to see as language 
construction becomes more popular how the art form evolves and shapes itself into something much different than what it is today. Literature changes, it goes through movements and is subject to history, and conlangs are as well. An interesting project that could emerge from this is documenting conlangs as art forms, and seeing how they have evolved from Tolkien's Elvish all the way to now, how they have changed in their construction and development.

As for this project, phonology is somewhat difficult to assess for these languages. Kesh, in particular, does not have that much of a developed phonology, but it does have a morphology, and maybe even a syntax. Ethnosyntax may be a more interesting lens to look at these languages, and even a lexical catalogue would tell much about the culture and the text itself. It is an interesting implication to see how sociolinguistics are represented through the texts, such as Sindarin's relation to Quenya, using ethnosyntax as a base.

Conlangs will grow. More will enter literature, popular culture, and the public consciousness. There is so much more to learn. Though Babel may be lost, its ashes scattered across the nations, it still lives on within us, breathed into the lungs of every living person, a particle expelled with every word spoken or signed or written and inhaled with every word read or heard. We may never know the first language. The beauty of the first word ever spoken may never be known by a living person. But the next language could have its genesis tomorrow. It could be the one that builds the tower. 


\section{References}

Adams, M. (2011). From Elvish to Klingon: exploring invented languages. Oxford: Oxford University Press.

Bianco, J. L. (2004). Invented languages and new worlds. English Today, 20(2), 8-18.

Boroditsky, L. (2011). How language shapes thought. Scientific American, 304(2), 62-65.

Call, L. (2007). Postmodern anarchism in the novels of Ursula K. Le Guin. SubStance, 36(2), 87-105.

Campbell, Lyle. (1998). Historical linguistics: an introduction. Edinburgh: Edinburgh University Press

Cheyne, R. (2008). Created languages in science fiction. Science Fiction Studies, 386-403.

Enfield, N. J. (Ed.). (2002). Ethnosyntax: explorations in grammar and culture. Oxford: Oxford University Press.

Faulkner, W. (1990). As I Lay Dying. 1930. New York: Vintage.

Jones, G. E. (1984). The distinctive vowels and consonants of Welsh. Welsh phonology: Selected readings, 40-64. Cardiff: University of Wales Press.

Lass, Roger (1998). Phonology: An introduction to basic concepts. Cambridge, UK; New York; Melbourne, Australia: Cambridge University Press

Le Guin, U. K. (1985). Always coming home. Berkeley: University of California Press. 
Le Guin, U. K. (1974). The dispossessed. London: Hachette UK.

Le Guin, U. K. (1969). The left hand of darkness. New York City: Ace Books.

Lee, S. D. (2014). A companion to JRR Tolkien (Vol. 189). Hoboken, New Jersey: John Wiley \& Sons.

Makdisi, S. (1995). Postcolonial literature in a neocolonial world: Modern Arabic culture and the end of modernity. Boundary 2, 22(1), 85-115.

Mortimer, P. (2005). Tolkien and modernism. Tolkien Studies, 2(1), 113-129.

Okrent, A. (2009). In the land of invented languages. New York: Spiegel \& Grau.

Peterson, D. J. (2015). The art of language invention: From horse-lords to dark elves, the words behind world-building. London: Penguin Books.

Salo, D. (2004). A Gateway to Sindarin: A grammar of an Elvish language from JRR Tolkien's Lord of the Rings. Salt Lake City: University of Utah Press.

Sanders, N. (2016). Constructed languages in the classroom. Language, 92(3), 192-204.

Timberg, S. (2009, May 10). "Ursula K. Le Guin's work still resonates with readers". Los Angeles Times. Retrieved from http://www.latimes.com/entertainment/arts/la-ca-ursulaleguin10-2009may10-story.html

Tolkien, J. (1991). The lord of the rings. Crows Nest, Australia: Allen \& Unwin.

Tolkien, J. (1977) The silmarillion. Crows Nest, Australia: Allen \& Unwin. 


\section{APPENDIX A: IRB Consent Form, David J. Peterson}

Be part of an undergraduate thesis

The Art of the Artistic Language: Examining Constructed Languages in Literary Fiction

Estephan Campisi from Portland State University's Urban Honors College, advised by Professor Kimberley Brown, $\mathrm{Ph} . \mathrm{D}$, is writing a thesis on constructed languages and how they develop in a writing process. This thesis will be a research and discussion of literature related to what constitutes a fully realized constructed language, their significance in enriching works of speculative fiction, and whether they can be critically analyzed as literature.

What will I have to do?

If you decide to take part in this project, we will:

- Send you a list of questions via email and ask you to answer them at time when it is convenient for you. The questions can be answered at any length you wish.

- Publish your statements non-confidentially in the completed thesis, which will be presented to an audience of peers and stored digitally for public access by the Portland State University Library.

Why have I been asked to take part in this study?

You have been asked to take part in this study because you are an accomplished author with a comprehensive background in constructing languages for works of fiction.

Are there any risks?

There are no risks to this study.

What are you doing to protect me?

Though your statements will be non-confidential and we will publish your name alongside your statements, we will email the selections we plan to use with their context in the paper for your final approval. If you wish any given statement not be published, we will not include it.

What happens if $\mathrm{I}$ decide not to take part in this study?

- You do not have to take part in this study. Your participation is voluntary.

- You can change your mind and stop at any time, even if you first said yes.

- The study will continue as a literature review.

Any Questions?

If you have any questions about this study, this form or the project you can:
- Email the researcher (Estephan Campisi, email: ecampisi@pdx.edu)

- Email the advisor (Dr. Kimberley Brown, email: dblbb apdx.edu

- Contact the Chair of the Human Subjects Committee of Portland State University about your rights as a research participant. They can be contacted at

The PSU Office of Research Integrity

1600 SW 4ti Ave., Market Center Bldg., Ste. 620

Portland, OR 97201

Telephone: $503-725-2227$ or $1-877-480-4400$; email: hsirc $a$ lists.pdx.edu

Hours: 9:00 a.m. to 5:00 p.m., Monday through Friday

If I sign, what does it mean?

This is a consent form. Your signature below means that:

- You have read and understand what this form says.

- You are willing to have your statements taken in the study via an email questionnaire and having those statements be published alongside your name in the thesis.

- You know that you do not have to take part in this study. And even if you agree, you can change your mind and stop at any time. No problem.

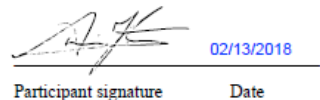

Participant name, printed 


\section{APPENDIX B: Email Correspondence with David J. Peterson (I: Interview, P: Peterson)}

I: Would you consider your conlangs, such as Dothraki in Game of Thrones or one of the many languages in Defiance, to be a product mostly of deliberation or of arbitrary judgement? For instance, are certain sounds chosen for a phonology because it makes sense why they would fit into the language and the culture behind it, or because it just seems to fit together well in an aesthetic sense?

P: The answer to both questions is either no for both, or yes for both. They haven't been asked quite right. There is no connection between culture and phonology-period. Those that say there is are often simply speaking from a history of exoticism. Also, when it comes to the sound of a particular root (because the roots are the only arbitrary parts of it), I sometimes do it based on what I want that word to sound like, or sometimes do it randomly. Sometimes I go against what I want it to sound like so my judgment doesn't color it. As long as it's phonologically and phonotactically licit, it can be a potential root in that language. This is purely for root creation, though. Very little else having to do with a language is arbitrary.

I: At what point would you consider a constructed language to be finished? Is there a bare minimum level for a constructed language to be valid?

P: A created language is never finished. Same as with a natural language. The only time it's finished is when the creator dies, but even then others can pick it up and use it and expand upon it if they want, and then it lives on in a different form, and continues to be unfinished. Instead, there are certain benchmarks one uses to evaluate the stages of a created language: When it can translate a simple text; when it can fill out a Swadesh list; when it can translate a longer text... It's a fuzzy boundary between a sketch and a full conlang.

I: At what point in the writing process do you normally begin to construct the language? Do you know the culture and people that speak it before you write the words?

P: That's certainly been the case for all the shows I worked on. I'm brought in at a point where the speakers have already been defined. As I flesh out the vocabulary, though, I help to flesh out the culture as well. This happens naturally in the course of vocabulary creation. 